\title{
05
}

\section{La Asociación Española de Museólogos cumple también 25 años con interrogantes en el horizonte}

\author{
Ana Carro Rossell \\ Asociación Española de Museólogos
}

El asociacionismo profesional de cualquier colectivo parte del convencimiento de que es imprescindible reflexionar con personas del mismo ámbito para decidir cuáles son las principales líneas de acción que se deben llevar a cabo en cada momento. Asociarse, unirse, luchar por un fin común, creer que se pueden mejorar o al menos sentirse capaz de cambiar o desafiar el estado de las cosas, creer que la visión personal no tiene por qué ser la correcta y que es necesario conocer la de otros muchos. Confundirse y aprender a rectificar con la ayuda de compañeros. Crear vínculos con quienes comparten un proyecto común, vínculos que promueven y facilitan una relación fluida y permanente entre profesionales e instituciones.

Para dar respuestas a las necesidades y demandas sociales necesitamos crecer profesionalmente cada día y, sin duda, la mejor manera es mediante el enriquecimiento mutuo entre especialistas que trabajan en la gestión de obras de alta significación histórica y cultural.

Los colectivos que, desde diferentes ámbitos, trabajan en patrimonio cultural tienen unos fines consensuados que todos y cada uno de los miembros comparten. La conservación, la investigación, la interpretación, la didáctica, la difusión y la promoción del patrimonio preocupan a los profesionales, y esta inquietud se sobrelleva mejor si es compartida.

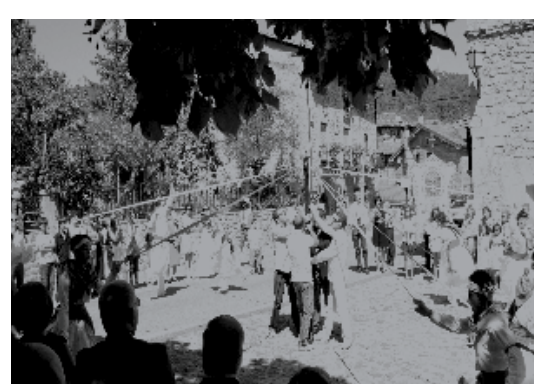

Una meta, un equipo. Danza Pradillo de Cameros (La Rioja) Foto AEM

El gran reto de estas entidades es reunir a personas que comparten los fines de la entidad, personas que se unen para trabajar, para aportar su experiencia y lograr el propósito marcado en su ámbito de conocimiento del patrimonio.

Desde la experiencia de la Asociación Española de Museólogos (AEM), que también cumple 25 años en 2018, consideramos que las asociaciones profesionales ofrecen una visión integral del trabajo en el campo de su orientación y proporcionan un marco de reflexión y debate sobre la función que cada colectivo debe asumir. Estas entidades facilitan y promueven los procesos de intercambio y transferencia de conocimiento y experiencias entre los investigadores del área y los agentes sociales, como base de un enriquecimiento que contribuye a mejorar. 
Aproximarse a la realidad nacional y mundial del patrimonio para mantenerse sensible a las necesidades y demandas sociales, reivindicar la importancia del desarrollo de la sociedad, en cuanto a la educación, los valores democráticos, la cultura, la economía, la identidad colectiva, la tolerancia, la cohesión social, el equilibrio tradición-modernidad y el uso constructivo del ocio es, sin duda, la aportación de estos grupos.

La AEM siempre ha trabajado con la intención de llenar un vacío existente y divulgar los principios de la museología, contribuyendo a favorecer la relación de los museos con la sociedad y a la mejora de estas instituciones. Con este objetivo nos planteamos diversas cuestiones:

¿Cuál es el papel que deben desempeñar los museos en la sociedad del siglo XXI y cuál debe ser su verdadera función?

¿Puede la institución museística seguir presentándose ante la sociedad solo como un lugar donde se custodian y exhiben las más apreciadas producciones que se han ido creando generación tras generación?

¿Qué espera la sociedad de nuestros museos?

¿Cuáles son sus perspectivas globales de crecimiento?

Desde los primeros momentos, la entidad ha trabajado en la promoción de las instituciones museísticas y de las relaciones culturales de cooperación en el ámbito educativo y científico entre los profesionales de España y los del resto del mundo.

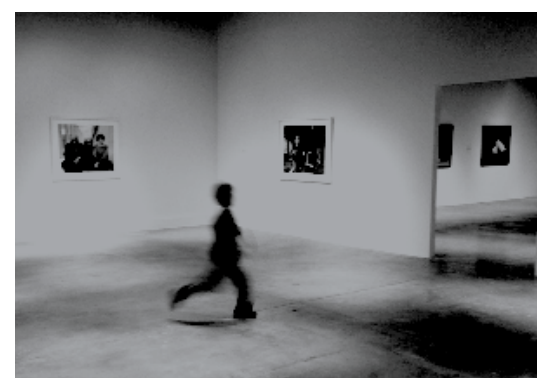

Los ciudadanos buscan estar presentes en los museos. Fuente https://pixabay.com/

Con las actividades que se realizan se pone al alcance de los participantes oportunidades para profundizar en el conocimiento y práctica de su especialidad, se dan a conocer las experiencias más innovadoras para desarrollar y aplicar los conocimientos, habilidades e instrumentos necesarios bajo criterios de eficacia, eficiencia y rentabilidad económica y social. Desde los comienzos, la AEM ha diseñado y gestionado diversas actividades formativas ante la demanda que recibía por parte de profesionales del sector y por el convencimiento de la necesidad de cubrir muchas lagunas en el campo de la formación. Los programas se han elaborado siempre partiendo de una idea básica: la actualidad.

Los profesionales del patrimonio deben intercambiar información y cualquier otro bien o servicio de interés con las administraciones públicas, organismos internacionales, universidades, empresas, asociaciones con fines similares y otros colectivos o entidades interesados. Las asociaciones profesionales trabajan para ello y son un vehículo de enriquecimiento para todos los agentes implicados. 


\section{"La AEM siempre \\ ha trabajado con la \\ intención de llenar un \\ vacío existente y divulgar \\ los principios de la \\ museología, contribuyendo \\ a favorecer la relación de \\ los museos con la sociedad \\ y a la mejora de estas \\ instituciones"}

Revista PH y Revista de Museología constituyen dos extraordinarios canales de divulgación que desde sus inicios ofrecen una visión integral y global del trabajo en el ámbito del patrimonio. El compromiso de estas publicaciones es continuar fomentando el intercambio de conocimientos y experiencias entre profesionales del sector, como base de un enriquecimiento que contribuya a una mejor gestión patrimonial.

El reto de cualquier asociación es representar a ciudadanos que buscan estar presentes de manera colectiva, defendiendo una causa o unos intereses comunes; es crear una comunidad en la que los socios son el activo más importante; es tener la capacidad para mantener los objetivos fijados a pesar de la falta de comprensión y apoyo por parte de los entes privados o públicos, o incluso de otros profesionales del sector.

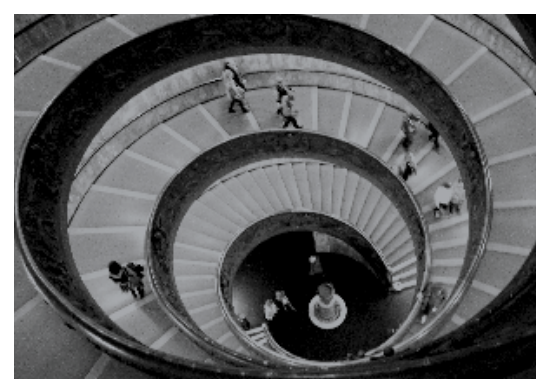

Museos Vaticanos. Escalera helicoidal de Giuseppe Momo (1875-1940)

Foto Nicolas Vadilonga

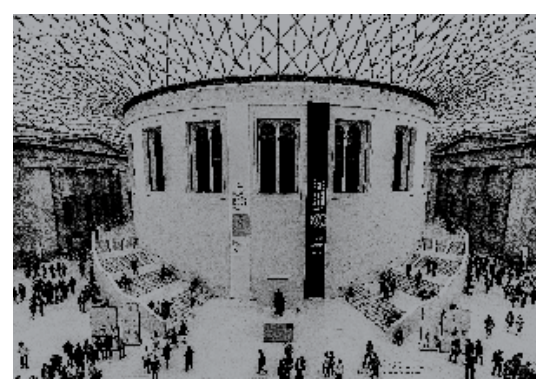

British Museum

Foto Pablo Fernández

Muchas cosas han cambiado en estos 25 años y el desarrollo que han conocido los espacios patrimoniales ha sido espectacular, en paralelo al desarrollo alcanzado a su vez por la sociedad española.

Aunque se resista 25 años, en el asociacionismo es necesario contar con la colaboración de todos y cada uno de los miembros para creer en un proyecto común al que nos hemos adherido con el convencimiento de que es necesario, o al menos conveniente. No debemos solo esperar servicios, sino, por el contrario, implicarnos activamente presentando propuestas, consiguiendo adhesiones para hacer crecer un proyecto colectivo que mejore nuestro quehacer con el patrimonio.

Aunque desde lo más profundo de nuestro ser creamos que nuestro proyecto ha contribuido a mejorar los espacios patrimoniales, debemos ser capaces de gestionar el cambio, de repensar nuestra acción.

Nuestra más sincera felicitación al Instituto Andaluz del Patrimonio Histórico por su magnífica publicación y por la extraordinaria labor realizada a lo largo de estos años. 